This article was downloaded by: [informa internal users]

On: 16 June 2009

Access details: Access Details: [subscription number 755239602]

Publisher Routledge

Informa Ltd Registered in England and Wales Registered Number: 1072954 Registered office: Mortimer House, 37-41 Mortimer Street, London W1T 3JH, UK

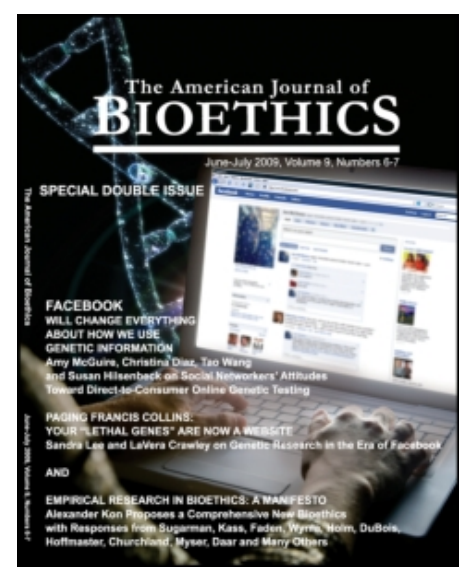

The American Journal of Bioethics

Publication details, including instructions for authors and subscription information:

http://www.informaworld.com/smpp/title content=t713606739

\title{
Personal Genome Testing: Do You Know What You Are Buying?
}

Heidi C. Howard a; Pascal Borry a

${ }^{a}$ Centre for Biomedical Ethics and Law, Katholieke Universiteit, Leuven, Belgium

First Published on: 01 June 2009

To cite this Article Howard, Heidi C. and Borry, Pascal(2009)'Personal Genome Testing: Do You Know What You Are Buying?', The American Journal of Bioethics, $9: 6,11-13$

To link to this Article: DOI: $10.1080 / 15265160902894005$

URL: http://dx.doi.org/10.1080/15265160902894005

\section{PLEASE SCROLL DOWN FOR ARTICLE}

\footnotetext{
Full terms and conditions of use: http://www.informaworld.com/terms-and-conditions-of-access.pdf

This article may be used for research, teaching and private study purposes. Any substantial or systematic reproduction, re-distribution, re-selling, loan or sub-licensing, systematic supply or distribution in any form to anyone is expressly forbidden.

The publisher does not give any warranty express or implied or make any representation that the contents will be complete or accurate or up to date. The accuracy of any instructions, formulae and drug doses should be independently verified with primary sources. The publisher shall not be liable for any loss, actions, claims, proceedings, demand or costs or damages whatsoever or howsoever caused arising directly or indirectly in connection with or arising out of the use of this material.
} 


\title{
Personal Genome Testing: Do You Know What You Are Buying?
}

\author{
Heidi C. Howard, Centre for Biomedical Ethics and Law, Katholieke Universiteit \\ Leuven, Belgium \\ Pascal Borry, Centre for Biomedical Ethics and Law, Katholieke Universiteit \\ Leuven, Belgium
}

Survey results from McGuire and colleagues (2009) imply that a portion of social networkers who responded to their questionnaire believe that personal genome testing (PGT) offers diagnostic information. They report that $34 \%$ (374/1087) of all survey respondents (including a majority who have not used PGT) believe the information provided by PGT to be a medical diagnosis, and 74\% (549/745) would consider using PGT for themselves "to see if a specific disease runs in family or is in DNA" (3). Moreover, of those who have used PGT, 60\% (38/60) consider the information obtained from PGT to be a diagnosis of medical condition or disease. This is of particular interest for many reasons, one of which being that many companies, including those mentioned in McGuire and colleagues' survey (2009) in fact, have statements or disclaimers on their websites stating that their services are not meant to have a medical purpose. 23andMe (Mountain View, CA) states in the terms of service section of their website "23andMe Service Is For Research and Educational Use Only. We Do Not Provide Medical Advice, and the Services Cannot Be Used For Health Ascertainment or Disease Purposes" (23andme 2009c). Regarding deCODE's (Reykjavik, Iceland) PGT service (known as deCODEme), one can find in their service agreement and informed consent section "The Genetic Scan product is for informational purposes only, is not medical advice, and is not a substitute for professional medical advice, genetic counseling, diagnosis, or treatment" (deCODE 2009c).

Meanwhile, on Navigenics' (Forest City, CA) website, there is, at the bottom of each page, in small, pale grey font, "Navigenics does not provide medical advice, diagnosis or treatment" (Navigenics 2009a). A similar statement is present in their terms and conditions section as well (Navigenics 2009b). This is worthy of mention, since McGuire and colleagues (2009) appeared to have grouped this company in a distinct category from 23andMe due to the fact that Navigenics staffs a physician and offers genetic coun- selling. Even with this increased 'health care'-customer support, which may make them appear more medically oriented, Navigenics shares the same type of disclaimer as the other two companies. Although analyzing the exact wording and details of each disclaimer is beyond the scope of this commentary, it is clear that as a group, the above mentioned companies claim that the PGT services they sell are not to be considered as medical advice or a diagnosis. Moreover, this is the case for many other companies selling direct-to-consumer (DTC) genetic tests. (Borry unpublished data) Kaye (2008) explains that these disclaimers have the dual role of providing information to customers as well as protecting companies from liability. As is suggested by McGuire and colleagues' (2009) report, however, whether consumers ever see and/or fully understand the information is debateable. Furthermore, these disclaimers can be considered as an acknowledgement of "the current lack of sensitivity and the poor predictive value of such tests" (Kaye 2008, R181).

The presence of such disclaimers on DTC genetic testing companies' websites raises, among others, two questions: 1) If these companies are not selling medical advice or diagnostic information, what are they selling? 2) Why do some people, including those who have used these services, (and who have, supposedly, looked at the website, at least long enough to order the service), consider the information provided as a form of medical diagnosis? Partial answers to both questions may be gleaned by considering some of the information these companies provide on their websites regarding what they do claim to be selling. It is important to note that there is a lot of variation between companies selling DTC genetic tests (Geransar and Einsiedel 2008) but a glimpse into those mentioned by McGuire and colleagues' survey (2009), provide statements such as the following: from deCODEme "the deCODEme service is an information service aimed at

Acknowledgment: Pascal Borry is funded by the Research Fund Flanders and Heidi C. Howard is funded by an International Incoming Marie Curie Fellowship (European Commission).

Address correspondence to Heidi C. Howard, Centre for Biomedical Ethics and Law, Katholieke Universiteit Leuven, Kapucijnenvoer 35 BOX 7001, 3000 Leuven, Belgium. E-mail: heidi.howard@med.kuleuven.be 
empowering you to get to know your genome" (deCODE 2009c); from 23andMe "At 23andMe our mission is to help our customers understand their own genetic information and how the current biomedical literature pertains to it" (23andme 2009a); from Navigenics "At Navigenics, we use the latest genetic science to illuminate the future of your health and provide you with the knowledge to change it for the better" (Navigenics 2009a). A common thread throughout these statements is that companies claim to be selling information, and in particular, genetic information.

The exact reasons explaining why some consumers are confused about the value of the PGT services would necessitate an entire study of its own; however, one could make general comments regarding this issue. For example, the location of claims and disclaimers on the website, and the size and colour of the font used to make these statements may contribute to confusion. A good example of this can be found on Navigenics' website. Under the "what we offer tab" on the home page, a consumer is welcomed with this message: "Navigenics gives you a view into your DNA, revealing your genetic predisposition for important health conditions. This level of personalization may help you take action to detect health conditions early, reduce their effects or prevent them entirely" (Navigenics 2009a). Meanwhile the disclaimer "Navigenics does not provide medical advice, diagnosis or treatment" (Navigenics 2009a) is present, in much smaller and paler print, at the bottom of each page of the company's web site. As for claims that could lead consumers to believe that they are purchasing medical advice or diagnostic information, one can consider the former statement from Navigenics along with the statements below. On the 23andMe website, under Health and Traits, one finds the title "A growing list of more than 100 diseases, conditions, and traits" (23andMe 2009b) followed by "The latest research on how your genes may affect risk for common diseases and conditions such as heart attack, arthritis and cancers" (23andMe 2009b). Furthermore, to the right of this, there is a list of traits and conditions for which 23andMe tests; these include, among others, age-related macular degeneration, colorectal cancer, heart attack, prostate cancer, and type 2 diabetes (23andme 2009b). On the deCODEme home page, under the title 'Complete Scan', one finds "Discover your Genetic risk for 38 diseases and traits ranging from Heart Attack and Diabetes to Alcohol Flush Reaction" (deCODE 2009b). Furthermore, under "how deCODEme works" the company states "deCODEme is a genetic health scan. Getting to know your personal genome will empower you and provide you with a road map to improve your health. In many cases, early detection of risk allows you to prevent a disease from ever taking hold" (deCODE 2009a). These are but a few selected statements, and as mentioned earlier, a full scale content analysis is beyond the scope of this commentary. Nonetheless, given the references to improved health and disease prevention along with the mention of serious disorders such as cancer and diabetes, it is not completely surprising that some consumers would believe PGT services to offer some form of diagnostic information and/or medical advice.
There is also a possibility that other sources of information are contributing to consumer (mis)understanding and expectations of PGT services. Consumers who have never even visited a PGT company's website could have easily gained information regarding these services from a number of popular media sources. Among others, Time Magazine (Hamilton 2009) and the Charlie Rose show (2008) have directly addressed the issue of DTC genetic tests. Furthermore, even YouTube (available at: www.youtube.com). turns up multiple hits if you enter 23andMe, or deCODEme or Navigenics as a search term.

In conclusion, consumers considering purchasing any genetic test sold directly to the consumer should read the terms of service and/or disclaimers carefully in order to make sure they are aware of what the company is offering. Moreover, possible consumer confusion regarding the medical value or interpretation of results is but one concern regarding DTC genetic testing highlighted by McGuire and colleagues' study. (2009). The fact that $78 \%$ of those who would use PGT services would also then ask help to interpret results from a physician could also be indicative of the possibility of gratuitous visits to the physician's office and consequent over-consumption of medical services. Furthermore, although 23andMe, deCODE, and Navigenics are often cited in articles, it is important to note that there exists more than 35 companies (Genetics and Public Policy Center 2009) selling DTC genetic tests. Simply because these companies are rarely mentioned, does not imply that their services are without controversy. Finally, it is becoming evident that these DTC genetic testing companies are pushing the boundaries of what has traditionally been understood as responsible genetic services. In response to this, there is a consensus that additional studies are needed in order to discover the effects that these services are having on consumers, and on the health care system, as well as regarding regulatory strategies that could best protect consumers. However, amidst these continuing academic studies and debates, above and beyond the 'read the fine print' advice given above, it would be disappointing, and to a certain degree, irresponsible if we lose site of the one thing that we do know now, and that we can share with consumers, which is, as articulated by Helen Wallace, that the "genetic information currently provided (by DTC genetic testing companies) is ... nearly all, to varying degrees, inaccurate, misleading or merely useless" (Wallace 2008, 1221).

\section{REFERENCES}

23andMe. 2009a. For Physicians. Avaiable at: https://www. 23andme.com/for/physicians/ (accessed March 9, 2009).

23andMe. 2009b. Health and Traits. https://www.23andme. com/health/ (accessed March 11, 2009).

23andMe. 2009c. Terms of Service. Avaiable at: https://www. 23andme.com/about/tos/ (accessed March 9, 2009).

Borry, P., Howard, H. C., Sénécal, K., and Avard, D. Unpublished data. Health-related direct-to-consumer genetic testing. A review of companies' policies with regard to genetic testing in minors. 
Charlie Rose. 2008. www.charlierose.com/view/interview/9194 (accessed March 9, 2009).

deCODE. 2009a. About deCODEme. Avaiable at: http://www. decodeme.com/about-decodeme (accessed March 11, 2009).

deCODE. 2009b. deCODEme Complete Scan. Avaiable at: http:// www.decodeme.com/complete-genetic-scan (accessed March 11, 2009).

deCODE. 2009c. deCODEme Genetic Scan Service Agreement and Informed Consent. Avaiable at: http://www.decodeme.com/serviceagreement (accessed March 9, 2009).

deCODE. 2009d. Frequently Asked Questions. Avaiable at: http:/ /www.decodeme.com/faq (accessed March 9, 2009).

Genetics and Public Policy Center. 2009. Direct-to-Consumer Genetic Testing Companies. http://www.dnapolicy.org/resources/ DTCcompanieslist.pdf (accessed March 9, 2009).

Geransar, R., and Einsiedel, E. 2008. Evaluating online direct-toconsumer marketing of genetic tests: Informed choices or buyers beware? Genetic Testing 12(1): 13-23.
Hamilton A. 2009. What Your Gene Test Can Tell You. Availabel at: http://www.time.com/time/magazine/pdf/best_invention_2008. pdf (accessed March 9, 2009).

Kaye, J. 2008. The regulation of direct-to-consumer genetic tests. Human Molecular Genetics 17(R2): R180-R183.

McGuire, A.L., Diaz, C.M., Wang, T., and Hilsenbeck, S.G. 2009. Social networkers' attitudes toward direct-to-consumer personal genome testing. American Journal of Bioethics 9(6-7): 3-10.

Navigenics. 2009a. Avaiable at: http:/ /www.navigenics.com/ (accessed March 9, 2009).

Navigenics. 2009b. Terms and Conditions. Available at: http:/ /www. navigenics.com/visitor/what_we_offer/our_policies/terms_conditions / (accessed March 9, 2009).

Navigenics. 2009c. What We Offer. Available at htttp://www. navigenics.com/visitor/what_we_offer/ (accessed March 9, 2009).

Wallace, H. 2008. Most gene test sales are misleading. Nature Biotechnology 26(11): 1221.

\title{
Direct-to-Consumer Personal Genome Testing: The Problem Is Not Ignorance-It Is Market Failure
}

\author{
Christopher F. C. Jordens, University of Sydney \\ lan H. Kerridge, University of Sydney \\ Gabrielle N. Samuel, University of Sydney
}

Direct-to-consumer personal genome testing presents a major challenge to healthcare systems because it distorts and confuses notions of diagnosis and screening and capitalizes on ignorance about causation for commercial ends. The reach of the Internet and the impact of globalization make this a global problem. In meeting this challenge we should be wary of calls to improve public and professional understanding of genetics, as they assume that the problem is ignorance so the solution must be education (the so-called 'Deficit Model'). We suggest that the problem is ultimately one of how to regulate testing in a poorly regulated free-market system where profits can be made in ways that generate costs for individual consumers and health systems. The global financial crisis has highlighted the social risks created by such systems, and the bioethics community should adopt a perspective that is wide enough to see the parallels in healthcare.
There is scant empirical research into direct-toconsumer personal genome testing (DTC-PGT), so we welcome the findings reported here (McGuire et al. 2009), notwithstanding the methodological limitations of the survey. The findings suggest that among people who build social networks online, a substantial proportion may consider using PGT for the purpose of gaining knowledge about disease in their family, and many would consider the results to somehow constitute a medical diagnosis, and would seek physician advice. If these findings are true, should we be concerned? And if so, on what grounds?

PGT is marketed and purchased for various reasons, including entertaining people's curiosity about their family background. We shall confine our comments to the value of DTC-PGT in providing information about possible health risks (or protective effects) conferred by the specific genes and polymorphisms tested in the genetic profiles currently

Acknowledgment: The authors thank Stacy Carter, Kim Strong, and David Macdonald for their comments on a draft of this manuscript. Address correspondence to Christopher F. C. Jordens, Centre for Values, Ethics and the Law in Medicine, Medical Foundation Building (K25), University of Sydney NSW 2006 Australia. E-mail: cjordens@med.usyd.edu.au 